\title{
Advertisement calls of Cuban toads of the genus Bufo (Anura, Bufonidae)
}

\section{Roberto Alonso and Ariel Rodríguez}

Department of Vertebrate Zoology, Institute of Ecology and Systematics. Carretera de Varona Km 31/2, Capdevila, Boyeros. AP. 8029, CP 10800. Ciudad de la Habana, Cuba. E-mails: robertoalonsous@yahoo.com, isel@fbio.fbio.uh.cu.

\begin{abstract}
Advertisement calls of Cuban toads of the genus Bufo (Anura, Bufonidae). The Bufo peltocephalus group is comprised of ten species of toads from the West Indies. Cuba hosts the highest diversity, with a total of seven endemic species. Adequated acoustic characterization of the vocalizations remained absent for the majority of these species. We offer some natural history data on their calling behavior, calling/breeding sites and describe the spectral and temporal characteristics of the advertisement call for all seven Cuban toads, five of which have not been described. The calls of each species differ from the rest in at least two of the examined parameters, particulary in dominant frequency and pulse rate. We observed two basic patterns of amplitude modulation. The first one, emitted by the three largest toad species, is characterized by long calls with trains of complex pulses. The second pattern, typical of the small and intermediate size species, includes short calls with trains of simple pulses.
\end{abstract}

Keywords: Anura, Bufonidae, Bufo, advertisement call, calling behavior, Cuba.

\section{Introduction}

Studies conducted during the last 30 years on the vocalizations in the genus Bufo have provided relevant information about the usefulness of the acoustic signals for species identification and have been used to examine phylogenetic relationships within this genus (Brown and Littlejohn 1972, Martin 1972, Cherry and Grant 1994, Cocroft and Ryan 1995, Gergus et al. 1997, Sullivan et al. 2000, Di Tada et al. 2001).

The Bufo peltocephalus group (Pramuk 2000) is a distinct lineage of toads that

Received 29 May 2003.

Accepted 15 November 2003.

Distributed 19 December 2003. comprises ten species endemic to the Greater Antilles, ranging from Western Cuba to the Virgin Islands. Seven of these species (Bufo cataulaciceps, B. empusus, B. fustiger, $B$. gundlachi, B. longinasus, B. peltocephalus and B. taladai) occur in Cuba. Bufo fluviaticus and B. guentheri inhabit Hispaniola and B. lemur is known from Puerto Rico and the Virgin Islands (Schwartz and Henderson 1991). Taxonomic research on the Bufo peltocephalus group has dealt with osteological (Pregill 1981, Pramuk 2000, 2002), morphological (Cei 1972, Graybeal and Cannatella 1995), and molecular data (Hedges 1996, Graybeal 1997, Hass et al. 2001, Pramuk et al. 2001, Pramuk 2002). These authors provided evidence of the monophyly of this group, postulating that these endemic West 
Indian toads originated from a mainland species from South or Central America.

The vocalizations of the Bufo peltocephalus group have received limited attention and for most of the species only onomatopoeic descriptions of these sounds are available (Schwartz and Henderson 1991). The main goals of this paper are to describe the spectral and temporal characteristics of the advertisement calls of the seven Cuban species of the Bufo peltocephalus group and to offer some natural history data on their calling behavior.

\section{Materials and Methods}

Recordings and call site data were obtained from all seven Cuban species comprising the Bufo peltocephalus group. Data were obtained from a single population of Bufo cataulaciceps, B. empusus, B. fustiger, B. gundlachi, B. longinasus, and $B$. peltocephalus. Two allopatric populations of $B$. taladai were recorded in eastern Cuba. Calls were generally recorded at night between 18:00 and 00:30 h; only the calls of $B$. longinasus dunni were obtained by day, between 10:00 and 12:30 h. Air temperature at calling sites was measured with a Miller and Weber quick-reading thermometer (error: $0.2^{\circ} \mathrm{C}$ ) immediately after each recording. Recording equipment included either a Sony WM-D6C or a Sony TCM59V and a Sennheiser ME 80 microphone, AKG D190E microphone or ultraminiature Radio Shack microphone. Calling toads were located with flashlights and the microphone was placed $50 \mathrm{~cm}$ in front of the caller.

The tape recordings were digitized at a sampling frequency of $22050 \mathrm{~Hz}$ and $16 \mathrm{bit}$ resolution using an IBM Pentium computer Sound card and Batsound 2.1 software. Audiospectrograms, oscillograms and power spectra were generated to quantify the temporal and spectral features of the advertisement call of each species. Two to eight successive calls from the middle of a call bout were analyzed for each individual. For B. fustiger, B. peltocephalus and $B$. taladai, species that produce long calls (>10 s), only two calls were analyzed. The peaks of amplitude modulation contained in the calls are referred to as pulses if the amplitude between two adjacent peaks decreased more than $50 \%$. Bufo fustiger has a diphasic advertisement call consisting of two distintic types of pulse trains or notes. We analyzed only the most regularly produced notes, considering note as the sound units produced by a single contraction of the body wall (McLister et al. 1995).

The acoustic variables considered were as follows. Call dominant frequency (DF) was measured to the nearest $0.02 \mathrm{kHz}$ in the power spectrum of a 12 pulse segment from the middle of each call. Since no frequency modulation was present in the advertisement calls of the seven species studied this system provides a good estimate of call DF (FFT 1024 points). Call duration (CD) was measured to the nearest $0.01 \mathrm{~s}$ on the waveform. The number of pulses per call (NP) was counted also on the waveform. Pulse rise time (PRT) was estimated as time in ms from pulse onset to peak pulse amplitude. Pulse rate (PR) was obtained calculating pulses/s for entire calls.

Oscillograms are presented for entire calls (Figure 1) and for a $250 \mathrm{~ms}$ section of the calls of each species showing the pulse structure (Figure 2). The summary of the numerical information obtained from sound analysis is shown in Table 1 . The range of temperature variation for all recordings never exceeded $4^{\circ} \mathrm{C}$, thus the influence of the air temperature on the acoustic features measured (Zweifel, 1968) should be minimal.

\section{Results}

\section{Calling Sites and Recording Data}

Bufo cataulaciceps Schwartz - Recordings were obtained in August 1999 in Los Indios Ecology Reserve, Isla de la Juventud, Cuba. Air temperature at the recording site was $23.0^{\circ} \mathrm{C}$. 
Bufo cataulaciceps males vocalize forming small choruses at dusk from flooded or poorlydrained terrain at open habitat of savannas. Males call among the dense herbaceous vegetation and are very difficult to locate.

Bufo empusus Cope - Recordings were obtained in September 1998 near the intersection between 100 Street and Rancho Boyeros Avenue, Ciudad de la Habana, Cuba. Air temperature near the recording site ranged between 24.8 and $26.0^{\circ} \mathrm{C}$. The chorus of $B$. empusus was sympatric with that of $B$. gundlachi, but males of these two species appear to select different calling sites. Males of B. empusus appear to choose more exposed calling sites at the edge of the water, where they were easier to find.

Bufo fustiger Schwartz - Recordings were obtained in May 2001 in San Juan River, El Taburete, Sierra del Rosario, Pinar del Río, Cuba. Air temperature at the recording site ranged between 23.0 and $26.0^{\circ} \mathrm{C}$. Males of $B$. fustiger formed loud chorus aggregations on the shorelines of montane rivers and water bodies, usually covered by gallery forest. Males called at night from the ground, positioned among the roots of the riparian vegetation, on the edge of water.

Bufo gundlachi Ruibal - Recordings were obtained in September 1998 near the intersection between 100 Street and Rancho Boyeros Avenue, Ciudad de la Habana, Cuba. Air temperature at the recording site ranged between 24.8 and $26.0^{\circ} \mathrm{C}$. Bufo gundlachi males vocalize in open areas, forming large choruses at night while floating in temporary pools in flooded lowlands, often surrounded or covered by grass, never totally exposed.

Bufo longinasus dunni Barbour Recordings were obtained in September 2001 in Codina Natural Park, Topes de Collantes, Sancti Spiritus, Cuba. Air temperature at the recording site was $22.0^{\circ} \mathrm{C}$. Males of $B$. longinasus dunni were recorded during the day in a slow flowing mountain creek where the males vocalized from exposed sites over the water, choosing logs, stones and even branches of trees up to $1 \mathrm{~m}$ above ground or water. This species appear to have a peculiar calling behavior, which includes climbing abilities and diurnal habits.

Bufo peltocephalus Tschudi - Recordings were obtained in May 2000 in the surroundings of Cienfuegos Botanical Garden, Cuba. Air temperature at the recording site ranged between 22.0 and $25.2^{\circ} \mathrm{C}$. Males of B. peltocephalus vocalized in similar conditions to $B$. fustiger, forming dense choruses in the edges of shallow and slowly running streams. This locality was not in a montane region and was not covered by forest.

Bufo taladai Schwartz - Recordings were obtained from two allopatric populations from Eastern Cuba: Manglarito, $2 \mathrm{~km}$ from Taco Bay in June 1999 and confluence of the rivers Yarey and Jaguaní in February 2000, both localities in Guantánamo Province. Air temperature at the recording sites ranged between 22.4 and $26^{\circ} \mathrm{C}$. At the first site the males called from the water in a flooded area among herbaceous vegetation; at the second, males were vocalizing in a noisy chorus at night entirely exposed standing on the shore of a montane river.

\section{Call Structure}

The long advertisement calls of B. fustiger, B. peltocephalus and B. taladai consist of periodic trains or notes (Figure 1A-C) composed of complex pulses which also contain internal amplitude modulations (Figure 2A-C). The pulse rise times of these three species pulses (typically above $40 \mathrm{~ms}$ ) are relatively longer than that of the rest of Cuban toads (Table 1). The calls of B. peltocephalus and B. fustiger are similarly composed of pulsed notes containing two or three amplitude modulations (Figure 2A,B), while the notes of $B$. taladai have four to seven pulses which contain rapid amplitude modulations (Figure 2C). The calls of these three species have most of the energy centered in a low frequency band, around $0.7 \mathrm{kHz}$ (Table $1)$. 
A
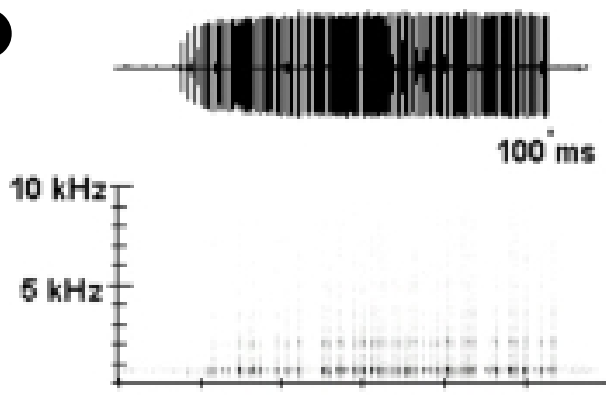

B
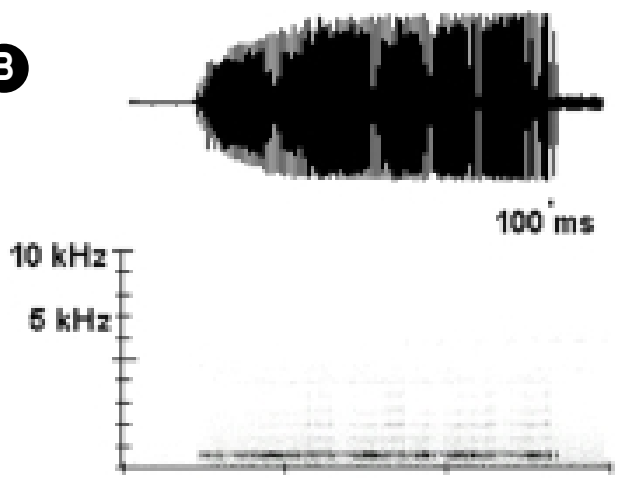

C

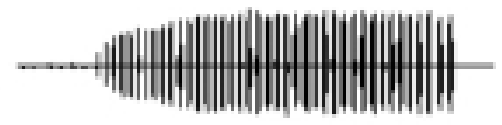

$100^{\circ} \mathrm{ms}$

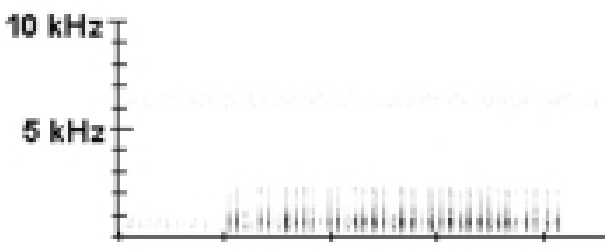

Figure 1. Oscillograms (top) and sonograms (below) of the advertisement calls of the seven species of Cuban toads of the Bufo peltocephalus group. (A) Bufo fustiger, (B) Bufo peltocephalus, (C) Bufo taladai, (D) Bufo empusus, (E) Bufo gundlachi, (F) Bufo cataulaciceps, (G) Bufo longinasus dunni.
(D)

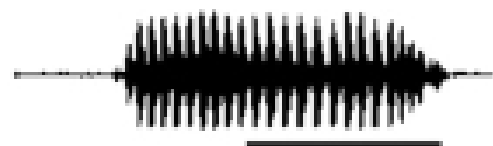

$100 \mathrm{~ms}$

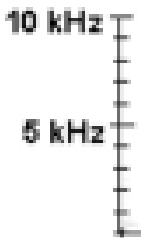

E

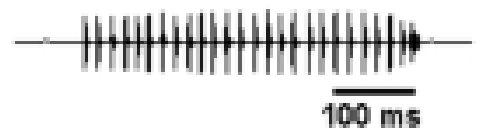

$10 \mathrm{kHz} F$

F
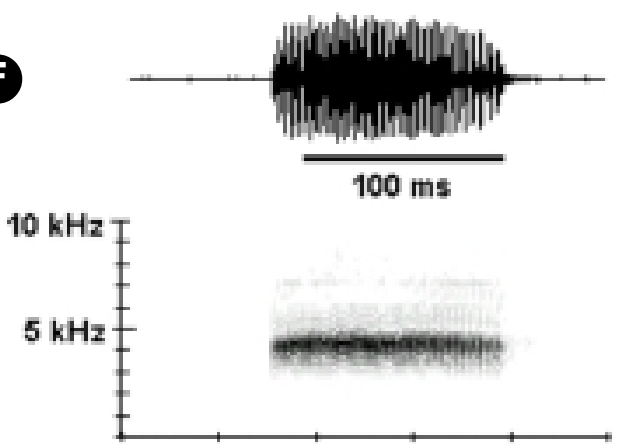

(
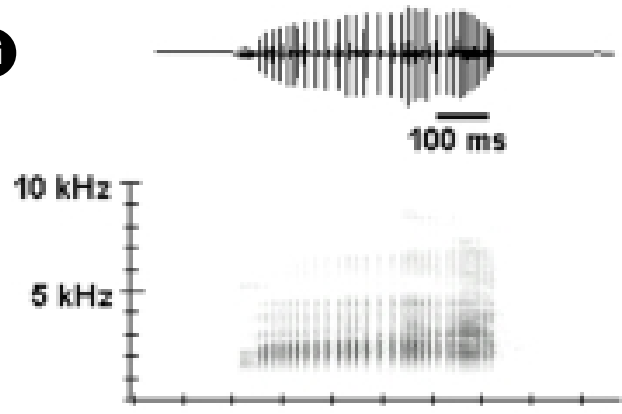

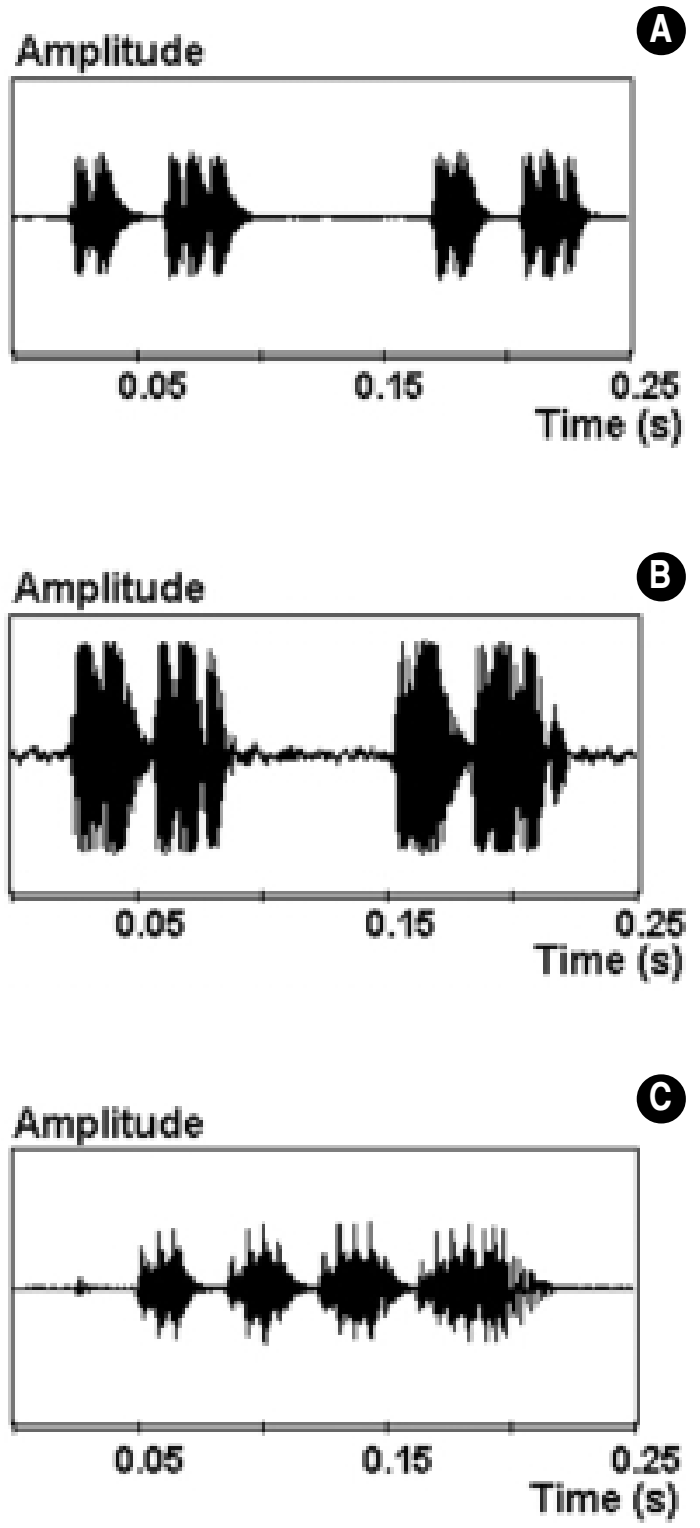

Figure 2. Oscillograms of a $250 \mathrm{~ms}$ section of advertisement call of the seven Cuban species of the Bufo peltocephalus group showing the fine temporal structure of the calls. (A) Bufo fustiger, (B) Bufo peltocephalus, (C) Bufo taladai, (D) Bufo empusus, (E) Bufo gundlachi, (F) Bufo cataulaciceps, (G) Bufo longinasus dunni.

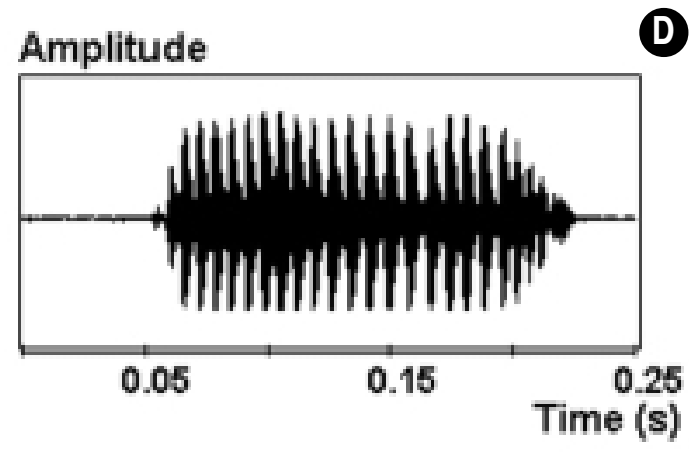

Amplitude

(E)

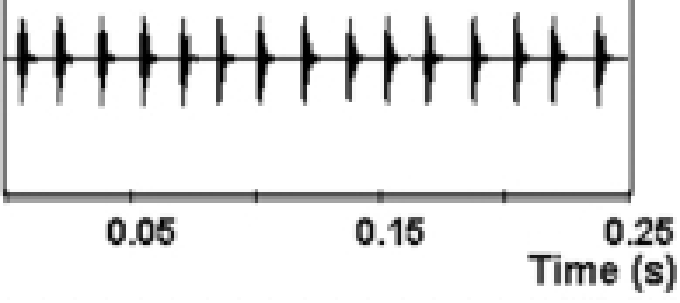

Amplitude

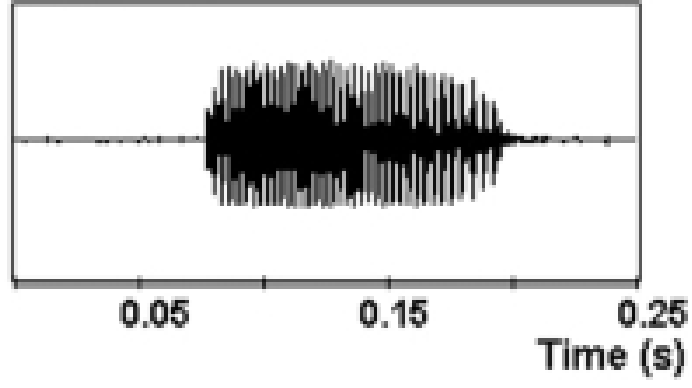

Amplitude

G

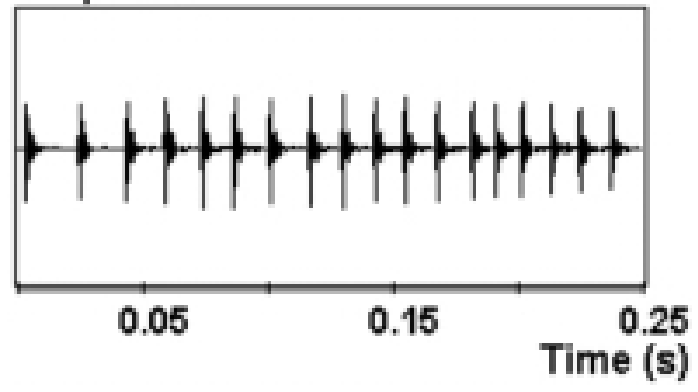


Table 1 - Acoustic characteristics (mean \pm standard deviation) of the advertisement calls of Cuban species of Bufo. N is the number of recorded males. DF, dominant frequency; CD, call duration; NP, number of pulses per call; PRT, pulse rise time; PR, pulse rate.

\begin{tabular}{lcccccc}
\hline SPECIES (N) & $\begin{array}{c}\text { CALLS } \\
\text { ANALYZED }\end{array}$ & DF (kHz) & CD (ms) & NP & PRT (ms) & PR (pulses/s) \\
\hline B. fustiger (11) & 22 & $0.712 \pm 0.015$ & $24.51 \pm 2.15$ & $97.4 \pm 32.8$ & $46.57 \pm 3.17$ & $3.9 \pm 0.2$ \\
B. peltocephalus (10) & 20 & $0.694 \pm 0.008$ & $14.57 \pm 1.11$ & $105.5 \pm 24.4$ & $41.61 \pm 4.14$ & $7.3 \pm 0.1$ \\
B. taladai (6) & 12 & $0.768 \pm 0.046$ & $11.91 \pm 1.18$ & $25.8 \pm 12.4$ & $110.11 \pm 26.26$ & $1.5 \pm 0.1$ \\
B. empusus (6) & 60 & $1.549 \pm 0.009$ & $0.21 \pm 0.03$ & $25.4 \pm 6.1$ & $1.57 \pm 0.23$ & $135.1 \pm 2.5$ \\
B. gundlachi (10) & 100 & $2.669 \pm 0.047$ & $0.46 \pm 0.03$ & $26.7 \pm 5.8$ & $1.18 \pm 0.37$ & $58.4 \pm 2.7$ \\
B. cataulaciceps (3) & 24 & $4.228 \pm 0.041$ & $0.12 \pm 0.01$ & $35.7 \pm 0.6$ & $0.49 \pm 0.03$ & $301.4 \pm 5.0$ \\
B. longinasus dunni (2) & 16 & $2.329 \pm 0.075$ & $0.41 \pm 0.07$ & $29.9 \pm 0.5$ & $0.86 \pm 0.01$ & $74.5 \pm 11.6$ \\
\hline
\end{tabular}

In contrast with the complex temporal structure of the advertisement calls of the large toads, the calls of Bufo empusus, B. gundlachi, $B$. cataulaciceps and $B$. longinasus consist of short trains of single pulses of similar duration and amplitude (Figure 1D-G) without any additional amplitude modulation (Figure 2D-G). These pulses have a faster rise time, below $2 \mathrm{~ms}$ (Table 1). In addition to the temporal differences, the dominant frequency of the advertisement calls of these small toads species is above $1 \mathrm{kHz}$ (Table 1).

\section{Discussion}

Most of the previous studies only provided onomatopoeic descriptions of the vocalizations of Cuban toads. Only Schwartz (1959), while describing the smallest toad from Cuba, Bufo cataulaciceps, offered for the first time graphical and numerical information about the acoustic features of the advertisement call for two Cuban bufonids (B. cataulaciceps and $B$. gundlachi). In his paper Schwartz miscalculated call duration and time between calls: the published sonogram for B. gundlachi (Figure 5 of Schwartz 1959) clearly shows that another neighboring toad was calling at the same time, resulting in an overlapping of the calls recorded and leading to a wrong interpretation of these two temporal features. Additionally we noticed that the sonograms of the advertisement call of B. cataulaciceps and B. gundlachi appear transposed in that paper (Figures 4 and 5 of Schwartz 1959). The values of frequency obtained by this author were approximately similar to our values, the slight differences could be related with the differences in technological improvement of recording and sound processing equipment or inter-populational variation.

The temporal structure of the advertisement calls of the Cuban toads can be assigned to the call types described by Martin (1972) for several species of Bufo. The pattern of amplitude modulation of the four small species with short pulsed sound having fast rise times corresponds to Martin's call type I. The pattern of amplitude modulation exhibited by the three large species with notes containing amplitude modulations corresponds to a typical type II call in the classification of this author. Probably, this subdivision of pulses in the advertisement call of the large species is due to the action of arytenoid valves in the larynx, as shown by Martin (1972) in his comparative study of call production in bufonids. 
Cocroft and Ryan (1995) observed notable variation in call duration and call rate within the Bufo cognatus group, although basic pulse structure has been conserved. According to the basic call structure, the Cuban species of the Bufo peltocephalus group would form two subgroups. The first subgroup (large toads) conserve a call structure based in trains of complex pulses, but with great differences in other temporal features (CD, NP, PR, and PRT), while the second subgroup (small species, including B. empusus) have a distinctive call structure, based on trains of simple pulses. The variation between both subgroups in other acoustic characteristics such as dominant frequency (correlated with the body size), pulses per call and call duration further contribute to differentiation among the species.

\section{Acknowledgments}

We are very grateful to F. Coro, M. Penna and R. Márquez for their helpful suggestions on earlier versions of the manuscript. Also Ron Heyer and an anonymous reviewer provided critical comments and editorial corrections that greatly improved the manuscript. Mario Penna and Rafael Marquez gave us full support and encouragement while recording and analysing the sounds. IDEAWILD provided the quickreading thermometer. The Third World Academy of Science (TWAS) and Agencia Española de Cooperación Internacional (AECI) partially supported travel and stay of the authors at the Program of Biophysics and Physiology of University of Chile and the Museo Nacional de Ciencias Naturales, Madrid, Spain, for the analysis of some of the signals included in this paper. The fieldwork was partially funded by the Cuban project Creación, Conservación y Manejo de Colecciones de Historia Natural of the Institute of Ecology and Systematics, Havana, Cuba.

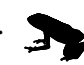

\section{References}

Brown, L. E. and M. J. Littlejohn. 1972. Male release call in the Bufo americanus group. Pp. 310-323 in W. F. Blair (ed.), Evolution in the Genus Bufo. Austin. University of Texas Press.

Cei, J. M. 1972. Bufo of South America. Pp. 82-92 in W. F. Blair (ed.), Evolution in the Genus Bufo. Austin. University of Texas Press.

Cherry, M. I. and W. S. Grant. 1994. Phylogenetic relationships and call structure in four African bufonid species. South African Journal of Zoology 29: 1-9.

Cocroft, R. B. and M. J. Ryan. 1995. Patterns of advertisement call in toads and chorus frogs. Animal Behaviour 49: 283-303.

Di Tada, I. E., A. Martino and U. Sinsch. 2001. Release vocalizations in neotropical toads (Bufo): ecological constraints and phylogenetic implications. Journal of Zoological Systematics and Evolutionary Research 9: 13-23.

Gergus, E. W. A., B. K. Sullivan and K. B. Malmos. 1997. Call variation in the Bufo microscaphus complex: implications for species boundaries and the evolution of mate recognition. Ethology 103: 979-989

Graybeal, A. 1997. Phylogenetic relationships of bufonid frogs and test of alternate macroevolutionary hypotheses characterizing their radiation. Zoological Journal of the Linnean Society 119: 297-338.

Graybeal, A. and D. Cannatella. 1995. A new taxon of Bufonidae from Peru, with descriptions of two new species and review of the phylogenetic status of supraspecific bufonid taxa. Herpetologica 51: 105131.

Hass, C. A., L. R. Maxson and S. B. Hedges, 2001. Relationships and divergence times of West Indian amphibians and reptiles: insights from albumin immunology. Pp. 157-174 in C. A. Woods and F. E. Segile (eds.), Biogeography of the West Indian patterns and perspectives. Boca Raton, FL. CRC Press.

Hedges, S. B. 1996. The origin of West Indian amphibians and reptiles. Pp. 95-128 in R. Powell and R. W. Henderson (eds.), Contribution to West Indian Herpetology - a tribute to Albert Schwartz. Saint Louis. SSAR.

Martin, W. F. 1972. Evolution of vocalizations in the genus Bufo. Pp. 279-309 in W. F. Blair (ed.), Evolution in the Genus Bufo. Austin. University of Texas Press.

McLister, J. D., E. D. Stevens and J. P. Bogart. 1995. Comparative contractile dynamics of calling and locomotion muscles in three hylids frogs. Journal of Experimental Biology 198: 1527-1538. 
Pramuk, J. 2000. Prenasal bones and snout morphology in the West Indian toads and the Bufo granulosus species group. Journal of Herpetology 34: 334-340.

Pramuk, J. 2002. Combined evidence and cladistic relationships of West Indian toads (Anura: Bufonidae). Herpetological Monographs 16: 121-151.

Pramuk, J., C. A. Hass and S. B. Hedges. 2001. Molecular phylogeny and biogeography of West Indian toads (Anura: Bufonidae). Molecular Phylogenetics and Evolution 20: 294-301.

Pregill, G. K. 1981. Cranial morphology and evolution of the West Indian toads (Salientia: Bufonidae): resurrection of the genus Peltophryne Fitzinger. Copeia 1981: 273-285

Schwartz, A. 1959. A new species of toad, Bufo cataulaciceps, from Isla de Pinos and Western Cuba.
Proceedings of the Biological Society of Washington 72: 109-120.

Schwartz, A. and R. W. Henderson. 1991. Amphibians and Reptiles of the West Indies - descriptions, distributions, and natural history. Gainesville. University of Florida Press. 320 pp.

Sullivan, B. K., K. B. Malmos, E. W. A. Gergus, and R. W. Bowker. 2000. Evolutionary implications of advertisement call variation in Bufo debilis, $B$. punctatus and B. retiformis. Journal of Herpetology 34: $368-374$.

Zweifel, R. G. 1968. Effects of temperature, body size, and hybridization on mating calls of toads, Bufo $a$. americanus and Bufo woodhousii fowleri. Copeia 1968: 269-28. 